ISSN 1112-9867

Special Issue

Available online at $\quad$ http://www.jfas.info

\title{
MOBILE APPLICATION TO ENHANCE WRITING SKILLS ABILITY AMONG DYSLEXIC CHILDREN: CiNTA
}

\author{
A. Z. Azmi ${ }^{*}$, N. H. Nasrudin, A. W. N. Wan and J. R. Ahmad \\ Faculty of Science Computer and Mathematics, UniversitiTeknologi MARA, 35400 Tapah, \\ Perak, Malaysia
}

Published online: 17 October 2017

\begin{abstract}
Dyslexia has been defined in different ways and it has been around for a long time. The World Federation of Neurologists in 1968 has defined dyslexia as a children who cannot get the good language skills of reading, writing and spelling corresponding with their intellectual abilities and a children who in condition that conformist classroom experience, weak to achieve the good grade in study. There are many mobile invention that has been created specialty for the Dyslexia Children. The mobile invention was more focusing on learning, writing and listening. With this mobile invention the learning process became attractive and fun for the Dyslexia Children. This research produce an apps known as CinTA acronym from Malay word "Cara Interaktiftulis Abjad". It has been implemented on the Android platform and focuses on the Dyslexic children who have problem in writing and recognizing characters.
\end{abstract}

Keywords: writing skills; dyslexic mobile apps; mobile invention; CinTA.

Author Correspondence, e-mail: anis9108@perak.uitm.edu.my

doi: http://dx.doi.org/10.4314/jfas.v9i5s.15 


\section{INTRODUCTION}

Dyslexia occurs because the brain jumbles or mixes up letters and words and they usually have a poor memory of spoken and written words [1]. It is due to an inability and difficulty in identifying the shape and the sound of the character [1-3]. In [4] said it has been estimated that up to $15 \%$ of children in Asia may have learning difficulties in one form or another. In addition, 60 to $80 \%$ of these children suffer from a specific learning or literacy problem called dyslexia (derived from a Greek word meaning "difficulty with words"). Here in Malaysia, it is estimated that up to 500,000 children per generation are facing various degree of dyslexia.

The main objective of this research is to produce a relevant learning material for dyslexic student. We must understand our target learner to find out the best solution [5-6]. We have done our groundwork study by observing dyslexic student learning process in their classroom and conducted an Interview with special school teachers from two special schools in Ipoh and Kedah, Malaysia. Research discovered that the students that have ability in writing have higher chances to recognize any character and read earlier rather then students who are not able to write. Therefore, writing skills ability becomes the scope in this research.

Since, recent study reveals that smartphones and tablets have become the preferred devices for many people with dyslexia [7]. The study tries to disclose existing apps that support or apply the suggested learning strategy. Profoundly, there are about 45 apps suggested in [8] that support the learning strategy and all apps are in IOS platform. Apparently, the widely used language in the apps is English and this language is mostly preferred or frequently used by the Apple users or children/parents who are proficient in the language [7-9]. Besides that, these apps only focus on the sound of the character but not on enhancing the writing skills. Android has been chosen as the best platform this application [10-12]. Thus, this research producesa mobile app in Android platform known as asCinTA acronym from Malay word "Cara InteraktiftulisAbjad" that give special focus on enhancing the writing skills ability among dyslexic children.

\section{METHODOLOGY}

\subsection{Programming and Software Use in CinTA Development}

Android Studio becomes as a tool in develop and designs CinTA. Whereas, Java as a core 
programming language compliment with Android SDK to transfer the storyboard design become reality.

Android Studio was interesting and user friendly software and being introduced in 2003. It has been released by Google and it integrated for other Google services. It facilitates by graphical user interface for dragging and dropping layout components or modifying XML file. Other then that, it also allows previewing the application layout on multiple screens. These features really help in developing CinTA according to the storyboard that has been reviewed and agreed by special school representative.

Furthermore, Audacity software has been used to edit the sound that has been used in CinTA. In the other hand, Adobe Photoshop CS6 and Adobe Illustrator CS6 has been used for editing any related photo or image in this mobile application.

\subsection{Design of the CiNTA}

The most important part of designing this application is the combination elements such as image, text, color, font style and font size to attract children interest when using this application. There are some criteria that have to emphasize for making an attractive design such as font size, font theme, and color. In [13] suggest some tips and guidelines for dyslexia people and it has been implemented in this application. Since dyslexic children more to illustration, imagination, tend to have a great sense humor and lots a love of fantasy worlds, the attractive design of this application plays an important role in order to attract dyslexic children.

\subsubsection{Font}

CinTA application has been chosen as a specific font for dyslexic children. In [13] recommending using Arial, Comic Sans Ms or, alternatives to these, Verdana, Tahoma, Century Gothic and Trebuchet using sans-serif font types for the dyslexic person to increase the reading performance. The text size also becomes the problem based on experienced by dyslexic people because the text was too small for the dyslexic people to read. The recommended size for dyslexics is twelve or fourteen points based on the participants that have participated in the dyslexic-friendly test by GaurangKanvinde the Director Accessible Systems from MadhavBaug Society, the dyslexic person requests a larger font to read. In this CinTA application, fourteen-point text size and Comic Sans Ms being chosen as a font type 
that using Sans-Serif with text being bold.

\subsubsection{Color}

Color also plays an important role in helping dyslexic children to learn actively when using this mobile application. The pure white and black background are not recommended for dyslexic children because it make the words swirl and get confusing. White backgrounds like a computer screen, white background of pages and whiteboard also make dyslexic children difficult to read.

CinTA applied the cream or pastel background color as suggested in [13]. Meanwhile, in [14] said that the lots of colors and illustrations being using can get dyslexic's attention and engage them emotionally. Table 1 will show the summary guidelines to design the mobile application of what are suggested and what are not suggested. CinTA application was designed base on this guideline.

Table 1. The suggested and not suggested rules for dyslexic children

\begin{tabular}{cc}
\hline Not Suggested to Dyslexic Children & Suggested to Dyslexic Children \\
\hline Less of color and illustration & More color and illustration \\
Use a larger writing task & Break large writing tasks down to smaller \\
Use a white background for all the & Avoided the white color background for all \\
Use a bright color as background & the material \\
Use a normal plain text type such as & Use a plain, sans serif font such as \\
Times & Arial,Comic Sans MS, Verdana, Tahoma \\
New Roman & Give instructions clearly and on active \\
Use long sentences for explanation & voice \\
Do not use text for dyslexic children & Use graphics, images and picture to break \\
Focusing learning time & uptext \\
Use text color based on the interest & givedyslexic children an education game \\
view of developer & Use a very bright and clear color text
\end{tabular}

Fig. 1 will show the sample pastel solid background that mostly used in this application. These colors are selected due it has a similar characterizes as a pastel color that can make 
dyslexic children read in clear view. Based on the guidelines given, these selected colors are suitable to use in this application.

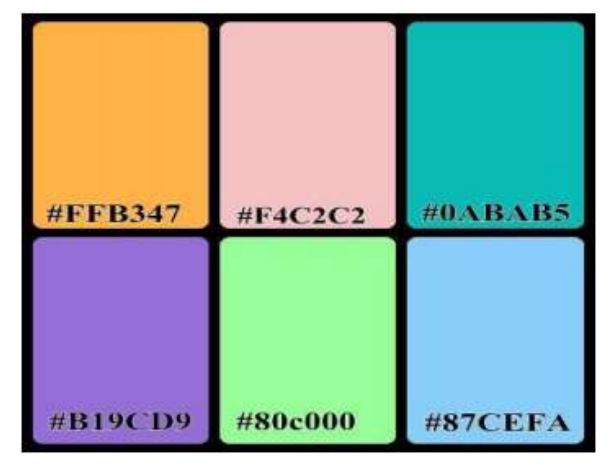

Fig.1. The sample pastel color with the color code

\subsubsection{Images and Sounds}

The main component to make this application can attract more attention from children is using images. About $90 \%$ images have been used in this application because dyslexic's world is a series of pictures, images and ideas. When the images been applied, children can learn easily, dyslexic's can create a story from the lesson that had been done. In [15] said graphics and images are suitable for dyslexic children because it can attract children and make the children more active in the program. So that, CinTA used an interactive images to represent all buttons covered by a beautiful background images to help children stay focus and interested to click the buttons and explore the application. Fig. 2 shows one of sample pages from CinTA application that using an images as a button that the images are familiar with dyslexic student.

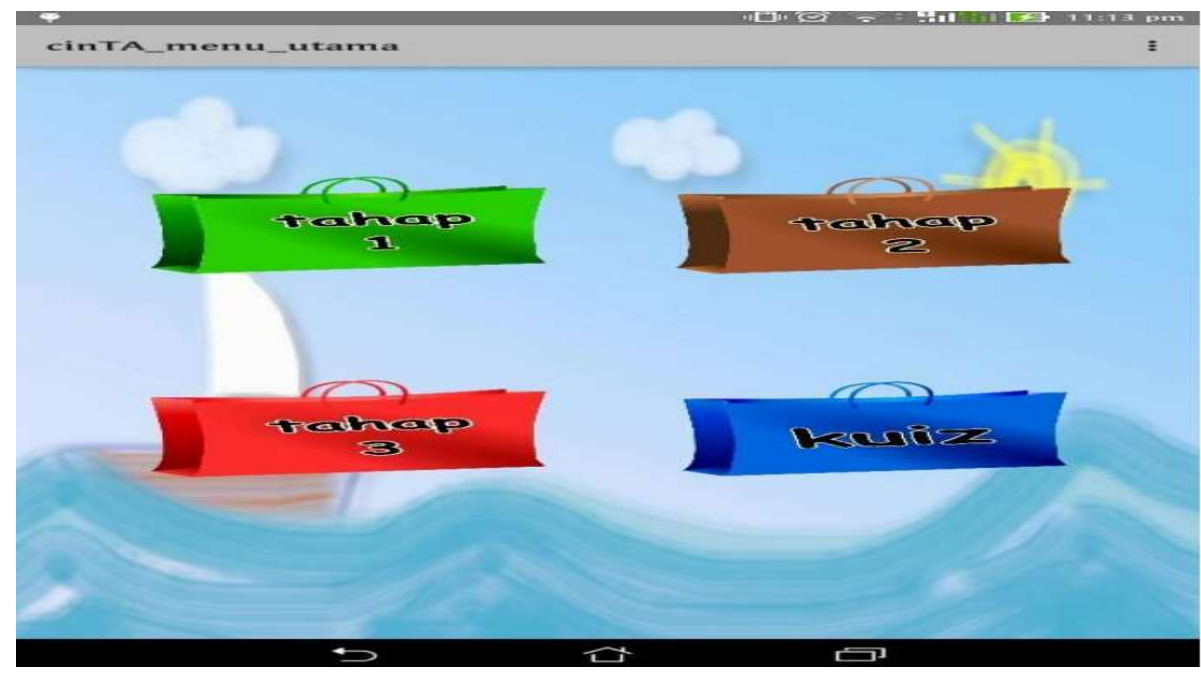

Fig.2.Sample pages in CinTA 
A beautiful image and buttons is not enough because the children may too young and do not have an idea about the function of the button. They may touch any image in the screen without any purpose and finally give up and close this application. To avoid this situation, CinTA help children by giving a voice instruction for every page as suggested by [16]. The instruction voice will be play automatically when the children open that particular page. CinTA also provide a voice instruction to the children once they touch the image button. A girl's voice has been decided to be used based on an analogy the children learn with their own friend. As a result, the children will feel freer and enjoy once they are well guided during learning session. Fig. 3 is the image buttons that represent vocal (yellow umbrella) and consonant (red umbrella) letter. Once children click on vocal image button an interactive page in Fig. 4 will be display.

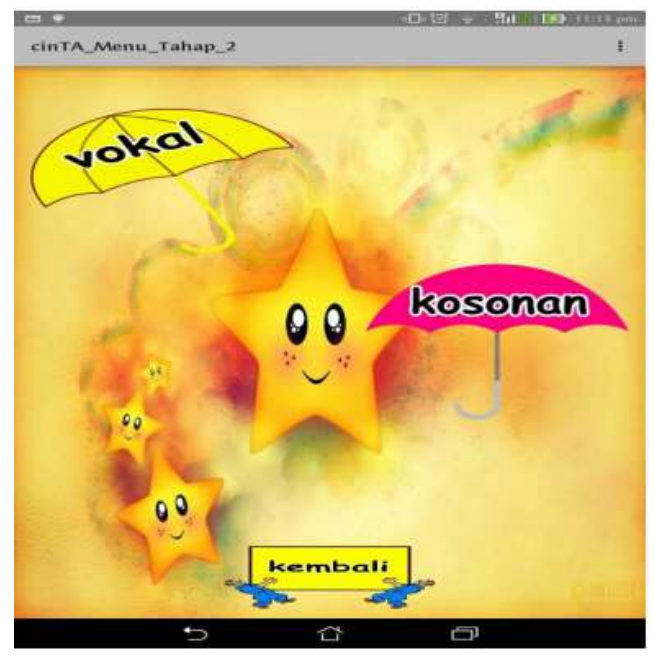

Fig.3.A voice instruction will be play once children touch the umbrella button

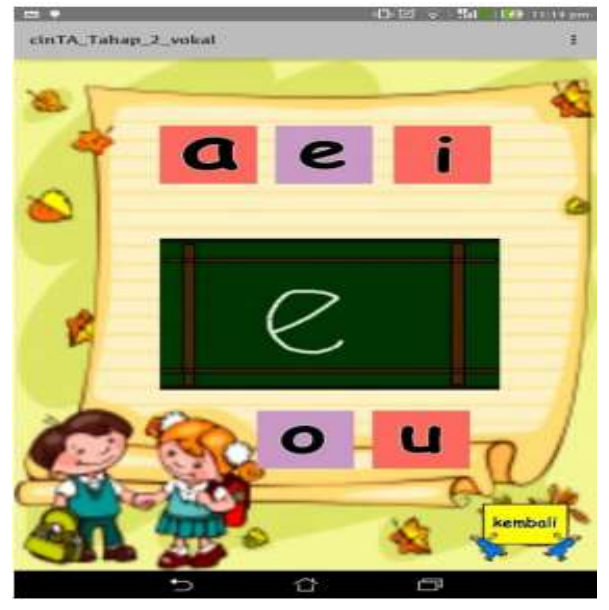

Fig.4.A vocal letter page. A video to write the character will be play in the chalkboard once 


\section{children click the letter}

\subsubsection{Special Writing Technique}

Based on the classroom observation and the interview that has been conducted with selected special schools in order to understand our learner. CinTA apply a special technique in writing a character to the dyslexic children. The techniques are technique letter ' $\mathrm{C}$ ' and technique letter ' 1 '. Letter ' $C$ ' and ' 1 ' will becomes a base in writing another character. For instance, from letter ' $C$ ' the student can write letter ' $d$ ' and 'o'. Special school representative said, these techniques are the most affective techniques in teaching dyslexic children in writing skills. CinTA will show to the student how to write the character with these techniques via a recorder video.

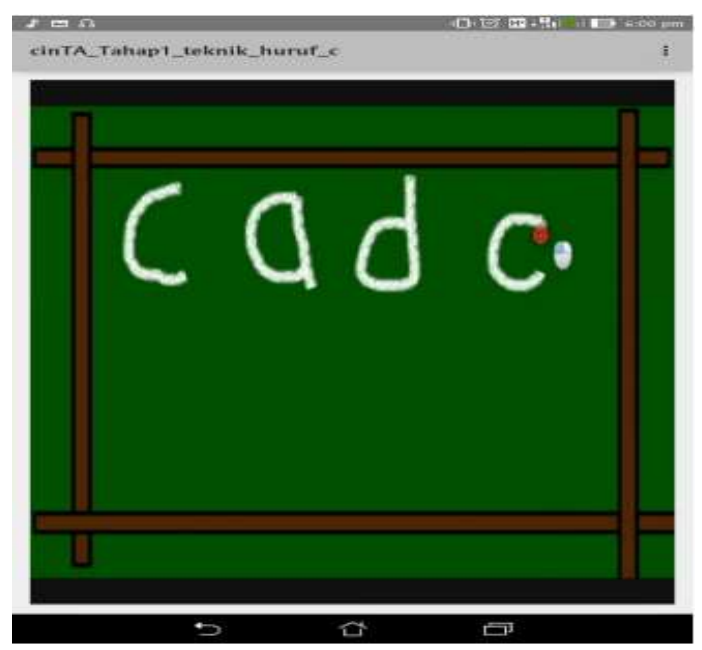

Fig.5. A video of letter ' $C$ ' technique. The writing technique will be complement with the narrator voice and ask children to write the letter together

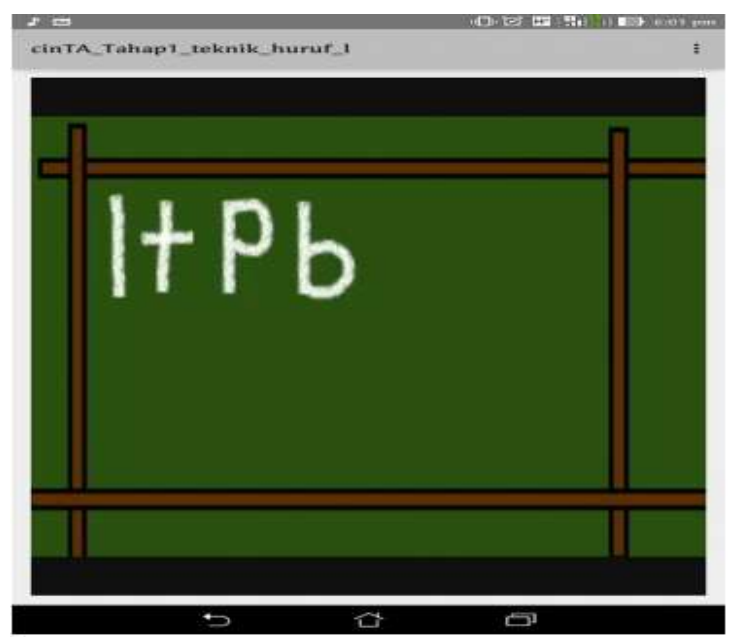

Fig.6. A video of letter ' 1 ' technique. The writing technique will be complement with the 
narrator voice and ask children to write the letter together.

\subsubsection{Interactive Quiz}

An interactive quiz was designed to evaluate children performance in a game mode. The design of this section is referred a guideline [17-18]. The pictures and story in this game is familiar within the children such as a school environment, clock and books. The quiz started with a simple game by giving an incomplete character (write in doted) and ask children to match the character with the options given such as shown in a Fig. 7.

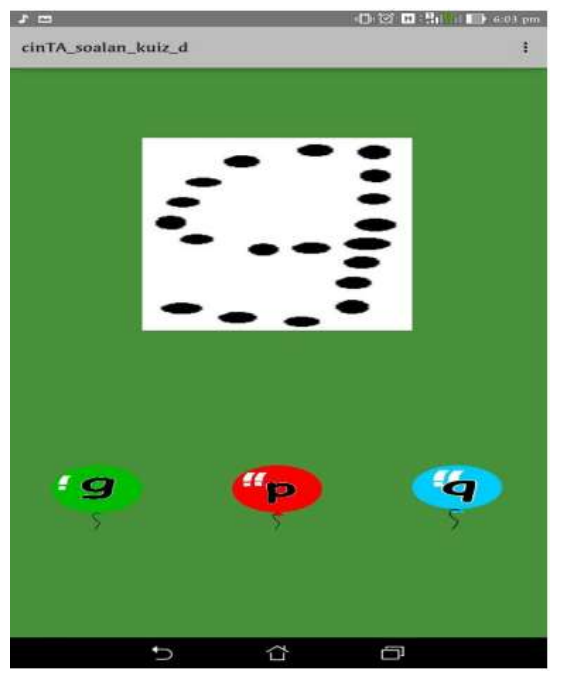

Fig.7. A voice instruction will ask children to chose the correct character which match with dotted character

For the second level of this game, the narrator will spell out the word clearly and ask children

to find a missing character from a given word. If the correct object is selected, cheer congratulation voice will be play to encourage children to answer the next question. 


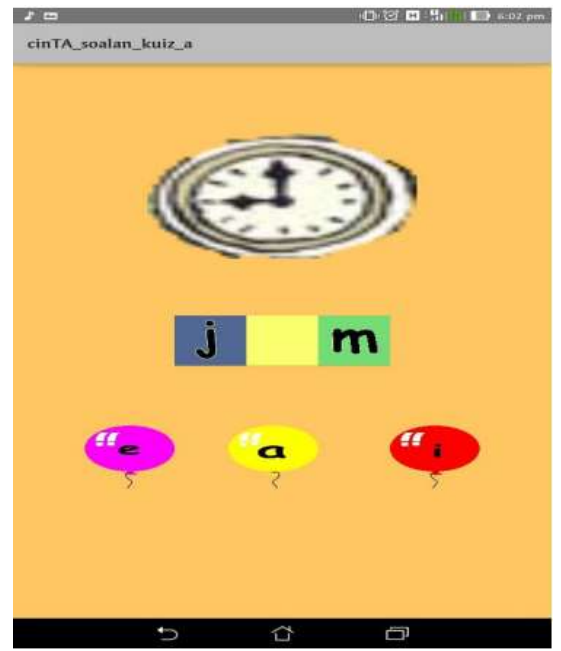

Fig.8. Children will asked to find the missing character ' $a$ ' by touch the correct bellon

The third level of this game is asking children to find an object according to the word given in the bottom of the page. The situation given is very close and familiar to them which is a classroom. Once children click the word the voice will read the word and ask children to find and click that object from the classroom. If the correct object is selected, the object will be blinking and a cheer congratulation voice will be play.

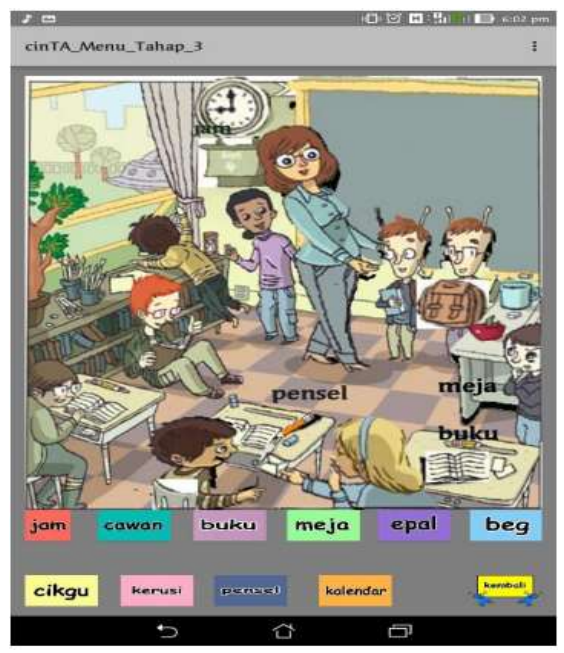

Fig.9. Children will asked to find the object based on word given

Finally, student performance will be evaluated and the total mark will be display at the end of the quiz session. 


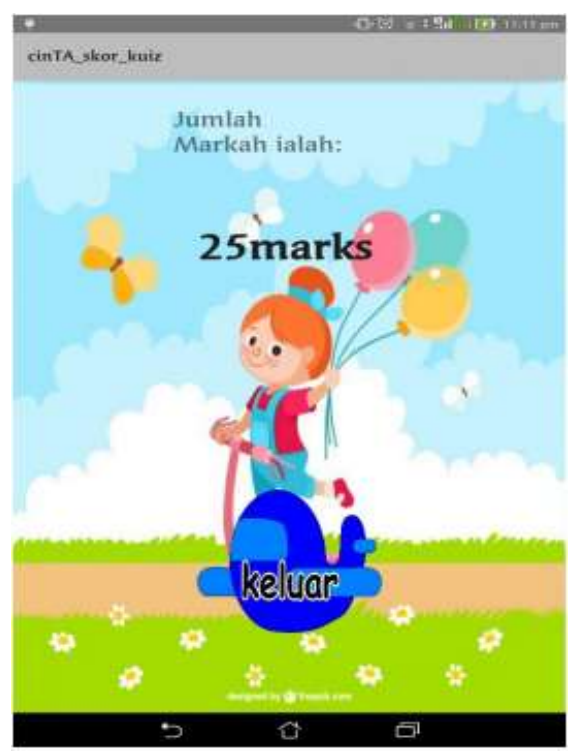

Fig.10. Total marks display at the end of quiz session as an evaluation

\section{RESULTS AND DISCUSSION}

CinTA has been tested and evaluated by five students that selected from SK Sultan Ahmad Tajuddin using a tablet within half an hour for each student. All five dyslexic children have completed the test based on the time given. CinTA application has brought up a new look on learning style for dyslexic children and the issues of acceptance, usability and preferences of CinTA has been asked. During the testing, positive response from student and teacher being taken and being evaluate.

During test application, the dyslexic children seem interested because the pages are attractive, simple and easy to use. Uses of images and graphics absolutely can help the dyslexic children to learn because they were focusing on image and listen to the voice that has been provided carefully. During alphabet video tutorial, it slowly attracts the dyslexic children because dyslexics follow the step with fingers on screen tablet and on the table. From the table, the performances of dyslexic children can be categorized based on a focusing level, how active dyslexic children with CinTA and children respond during learning lesson. 


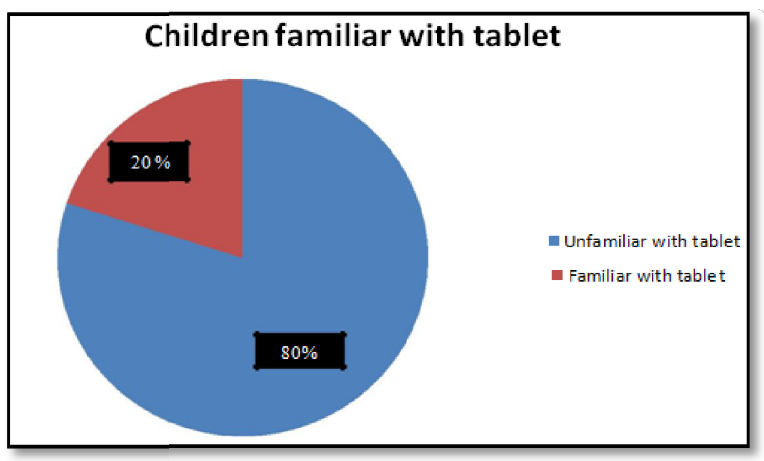

Fig.11. Children familiar with tablet

Fig. 11 shows that from five students that having dyslexic children only $20 \%$ per student are looking familiar with tablet or smart phone. Based on the question had been asked for dyslexic children, the uses of tablet are using at the house after school time for children making some revision. From the result, it can conclude that $80 \%$ of students are not come from wealthy family or parents does not teaching the children to addicted with smart phone and not familiar to using any modern technologies before this.

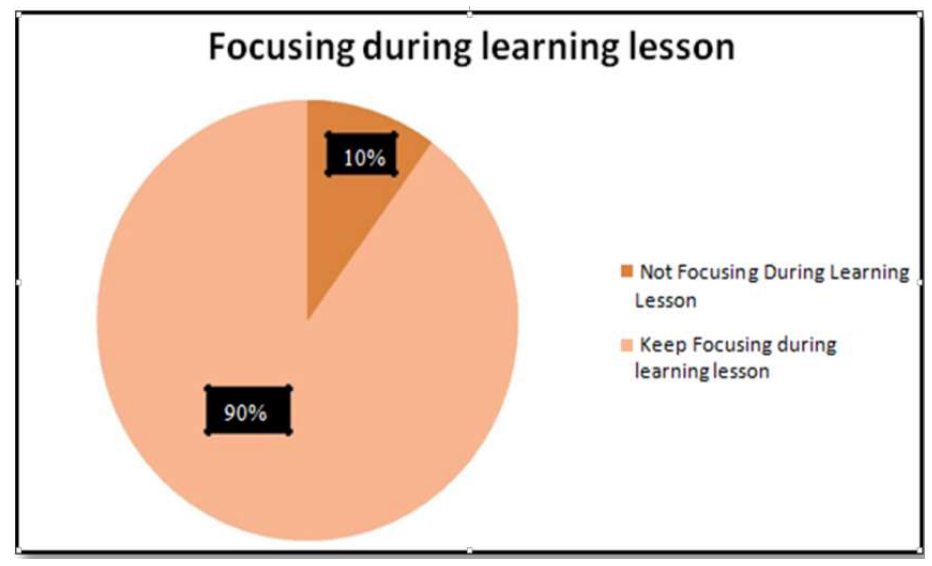

Fig.12.Focusing during learning lesson

Based on chart in Fig. 12, only $90 \%$ are keeping focusing because dyslexic children attract to the CinTA application but only one children who not focusing during quiz session. Analysis found, in quiz section the images and the background color are solid and less interactive rather than in leaning section that use lots of color and illustration. 


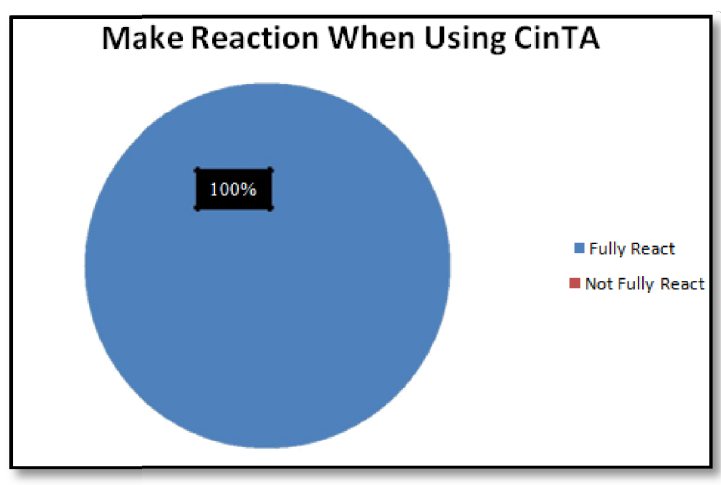

Fig.13. Make reactions when using CinTA

Fig. 13 shows that $100 \%$ students are show a reaction and give positive response to the tester after using it. Dyslexic children also make a communication with a tester during the test session. When the videos in writing technique ' $C$ ' and ' $l$ ' is playing, children focuses on the video and dyslexic's finger slowly follows on how to write alphabets on the tablet screen. Furthermore, there are some students can guess an alphabets before the video finish the writing. During all the activity, dyslexic children keep hearing, saying and spoken out words and alphabets together with sound in the application. In this case, the use of multimedia element and guideline that has been applied in CintA are really helpful.

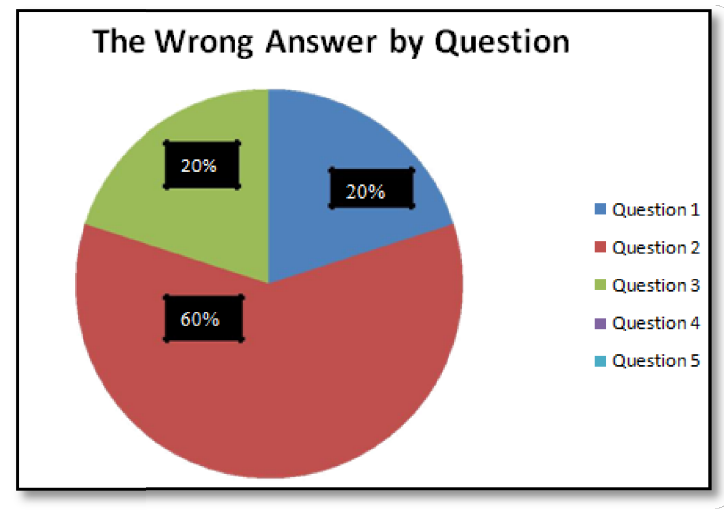

Fig.14. The wrong answer by question

Fig. 14 show that the type of question in quiz that dyslexic children get wrong and cannot answer it well. The wrong answer by question that commonly making a mistake is the children confusing because the voice said ' $\mathrm{j}$ ' but the children answer ' $g$ ' evens the sound of the image spell one by one. It shows that children still confusing with the letter ' $\mathrm{g}$ ' and ' $\mathrm{j}$ ' by sound and see it or the picture and sound uses is not clear to see and hear. Question 4 and 
Question 5 are clearly to answer because the questions are simple and easy to discover.

Feedback survey has been distributed to the teacher, MrsNorHayati Ismail from SK Sultan Ahmad Tajuddin, Kedah that was conducted to teach dyslexic children and discover a signs of dyslexia. This survey is for feedback of improvement of dyslexic children after using CinTA application.

The feedback result from teachers, MrsNorHayati Ismail being categorized to four sections whereas first section is feedback about dyslexic student, learning content, design of the application and the feedback from teacher.

The teacher response towards children give a good attention during learning session because an attractive background, the suitable voice, clear instruction and clear technique was being use in CinTA. It was lead to the better performance of the student due to the new learning method and approach. Besides, CinTA help her to reduce the individual learning time in her classroom.In tearm of learning content, she said CinTA is suitable for dyslexic children and to write and identify the alphabets or character. The sound that has been chosen also clear, but the she prefers to use an adult voice in future enhancement. In the other hand, the navigation flow of CinTA is easy to be understood by children.

\section{CONCLUSION}

CinTA application proves that technologies are adapted in education it really helps our society. Multimedia component that has been applied according to the proper guideline encourage dyslexic children keep more focus and give all the attention to the learning session and the performance of student are amazingly increased. The crux of the matter, learning time becomes more efficient and effective whereas teacher can reduce the individual teaching time process.

\section{ACKNOWLEDGEMENTS}

We would like to thanks our university, UniversitiTeknologi MARA Perak branch to permits to conduct and complete this research and contribute the result to the society. Special also given to teachers and children in SK Sultan Ahmad Tajuddin, Kedah that given their full commitment and support from the beginning till the end of our project. 


\section{REFERENCES}

[1] Høien T, Lundberg I. What is dyslexia? InTorleivHøien, \&Ingvar Lundberg (Eds.), Dyslexia: From theory to intervention. Amsterdam: Springer, 2000, pp. 1-20

[2] Steven M, Joseph H F, Rapin I J. Developmental medicine and child syndromes dyslexia in children and young adults: Three independent neuropsychological syndromes.Developmental Medicine and Child Neurology, 2008, 17(2):150-163

[3] Shaywitz S E, Shaywitz B A. Dyslexia (specific reading disability). Biological Psychiatry, 57(11):1301-1309

[4] Ambrose P P, Loh S C. Effects of the clay modeling program on the reading behavior of children with dyslexia: A Malaysian case study.The Asia-Pacific Education Researcher, 2013, 20(3):456-468

[5] Purcell G V, Duke N K, Martineau J A. Learning to read and write genre-specific text: Roles of authentic experience and explicit teaching. Reading Research Quarterly, 42(1):8-45

[6] Grolnick W S, Ryan R M. Autonomy in children's learning: An experimental and individual difference investigation. Journal of Personality and Social Psychology, 1987, 52(5):890-898

[7] Clare P. We recognize words like we do faces. 2015, http://www.abc.net.au/science/articles/2015/03/25/4203916.htm.

[8] Godwin J R. Emerging technologies: Mobile apps for language learning.Language Learning and Technology, 2011, 15(2):2-11

[9] iKidsABC. About. 2016, http://ikidsabc.com/about/.

[10]Lee C. Deployment of mobile learning course materials to Android powered mobile devices. International Journal of Distance Education Technologies, 10(3):1-16

[11] Pendell K D, Bowman M S. Usability study of a library's mobile website: An example from Portland State University. Information Technology and Libraries (Online), 31(2):45-62

[12] Goadrich M H, Rogers M P. Smart smartphone development: iOS versus Android.In 42nd ACM Technical Symposium on Computer Science Education, 2011, pp. 607-612

[13] Rello L, Kanvinde G, Baeza Y R. Layout guidelines for web text and a web service to improve accessibility for dyslexics.In 21st ACM International Cross-Disciplinary Conference on Web Accessibility, 2012, pp. 1-9 
D.

Writing

with

dyslexia,

2004,http://www.creative-writing-solutions.com/writing-with-dyslexia.html.

[15] Abtahi M S. Interactive multimedia learning object (IMLO) for dyslexic children. Procedia-Social and Behavioral Sciences, 2012, 47:1206-1210

[16]Mayer R E, Heiser J, Lonn S. Cognitive constraints on multimedia learning: When presenting more material results in less understanding. Journal of Educational Psychology, 2001, 93(1):187-198

[17] Special Education Support Service. 2006, Inclusive dyslexia-friendly practice. http://www.sess.ie/sites/default/files/Categories/Dyslexia/Dyslexia_crossborder.pdf.

[18] Texas Education Agency. Guidelines for examining phonics and word recognition.Austin: Texas Education Agency, 2002

\section{How to cite this article:}

Azmi AZ, Nasrudin NH, Wan Azman WN'Ahmad Junid R. Mobile application to enhance writing skills ability among dyslexic children: CiNTA. J. Fundam. Appl. Sci., 2017, 9(5S), 195-209. 